\title{
Leitoras e Leituras: Acesso orientado e questões de gênero*
}

6

Readers and Readings: Guided Access and Gender Issues

Larissa Akabochi de Carvalho*

* Recebido em: 01.02 .2017

Aprovado em: 20.05.2017.

${ }^{1}$ Mestra em Ciência da Informação pela ECA/USP. Email larissa.akabochi@gmail.com
Resumo: Historicamente, algumas leituras foram consideradas proibidas para o sexo feminino. Embora nem todas as mulheres se submetessem às proibições, a censura estava presente e dificultava a apropriação da informação. Com o desenvolvimento da tecnologia na segunda metade do século XX, facilitou-se o acesso. Porém, os meios de comunicação continuam a veicular informações marcadas pelas diferenciações de gênero. Através de uma análise quanto às indicações de leitura presentes nas revistas Claudia e Marie Claire e nos programas de televisão Saia Justa e Mais Você, verificou-se que esses meios costumam indicar livros de modo estereotipado. Em outras palavras, ainda existe um acesso orientado de leitura para as mulheres, através de fontes de informação direcionadas ao público feminino. Para analisar a questão das leitoras e a recepção desses livros indicados para elas, considerou-se a terceira edição da pesquisa Retratos da Leitura no Brasil e a comunidade virtual Skoob.

Palavras-chave: Leitora. Leitura. Gênero. Acesso Orientado.
Abstract: Historically, some readings were considered banned for females. Although not all women submitted to bans, censorship was present and made it difficult to appropriate the information. With the development of technology in the second half of the twentieth century, access was facilitated. However, the media continue to convey information marked by gender differentiation. Through an analysis of the indications of reading present in the magazines Claudia and Marie Claire and the television programs Saia Justa and Mais Você, it was verified that these means usually indicate books in a stereotyped way. In other words, there is still a read-oriented access for women, through sources of information aimed at the female audience. The third edition of the Portraits of Reading in Brazil and the Skoob virtual community was considered in order to analyze the issue of the readers and the reception of these books indicated for them.

Keywords: Reader. Reading. Genre. Access Oriented. 


\section{Introdução}

Por muito tempo, as mulheres foram excluídas do processo de alfabetização e letramento. Foi apenas no século XVII que houve uma reforma educacional promovida pela ascendente burguesia e, assim, começaram as discussões a respeito da educação da mulher (LAJOLO e ZILBERMAN, 2003). Contudo, as oportunidades não foram as mesmas para homens e mulheres. Enquanto eles frequentavam as escolas desde crianças para aprenderem uma profissão, elas deveriam ser suficientemente alfabetizadas para que pudessem ler o livro das rezas e ensinar as primeiras letras e operações matemáticas aos seus filhos. Desse modo, não chegavam a aprender um ofício nem a praticar a leitura e a escrita plenamente (HELLER, 2001). "Ao contrário: temia-se que mulheres letradas pudessem ler romances considerados perigosos à boa conduta e pudessem trocar bilhetes amorosos. A leitura, portanto, deveria ser vigiada e controlada. De preferência, pelo marido, pelo pai ou pela Igreja" (HELLER, 2001, p.2).

Algumas mulheres liam escondido da família e do marido. Porém, nem todas podiam fazer isso porque, além da desigualdade de gênero, apenas às mulheres abastadas era permitido o acesso ao mundo das letras (PINHEIRO, 2011). Mesmo assim, esta acessibilidade ainda era controlada pela voz masculina e pelas regras de convivência social, baseadas em pressupostos moralreligiosos, os quais dificultaram, por um longo período, a aproximação entre o gênero feminino e o processo de leitura e de escrita (PINHEIRO, 2011, p. 71)

Atualmente, homens e mulheres podem acessar qualquer tipo de informação impressa ou tecnológica. No entanto, ainda existe um acesso orientado de leitura através de fontes de informação que se intitulam como femininas. É o caso das revistas Claudia e Marie Claire e dos programas Saia Justa e Mais Você. Uma análise nesse sentido é importante para se pensar as leitoras de hoje, ou seja, o que as mulheres têm lido na atualidade. Ao observar o conteúdo das revistas e dos programas, bem como as suas indicações de leitura, é possível verificar uma manutenção de estereótipos de gênero. E ao analisar uma comunidade virtual para compartilhamento de leituras, a Skoob, nota-se que a recepção pretendida pelas fontes é confirmada pela grande quantidade de leitoras que leem os livros indicados e, inclusive, pelos seus comentários em relação às leituras.

Esta pesquisa foi fruto de uma dissertação de mestrado e teve como referência o período de 2011 e 2012. Com base nela, este artigo propõe-se a fazer alguns apontamentos sobre o processo de educação das mulheres e o controle que foi realizado, historicamente, a respeito do que elas deveriam ler. Passando para os dias atuais, verifica-se que este controle ainda continua, embora mais sutil, através de orientações de leitura em revistas e programas tidos como femininos. Determinados livros ainda são considerados para mulheres devido ao imaginário de mulher que prossegue na 
mente da sociedade.

\section{Leitoras, leituras e gênero}

O homem foi, historicamente, representado como o positivo e o neutro, a ponto de dizerem "os homens" para designar os seres humanos. Desse modo, a humanidade constituiu- se pelo masculino, e o homem definiu a mulher não em si, mas relativamente a ele, desconsiderando-a como um ser autônomo. A mulher foi determinada e diferenciada em relação ao homem e não este em relação a ela. A fêmea seria o inessencial perante o essencial. O homem seria visto como o Sujeito e o Absoluto, enquanto ela se constituiria como o Outro (BEAUVOIR, 1970, p. 9 e 10). De acordo com Spivak (2010), apesar de homens e mulheres serem objetos da historiografia colonialista, a construção ideológica de gênero manteve a dominação masculina. Se, no contexto da produção colonial, o sujeito subalterno não teve história e foi impedido de falar, o sujeito subalterno feminino ficou ainda mais profundamente na obscuridade.

A partir do século XVIII, a dimensão ética da educação feminina passou a ter também um valor econômico por gerar um alto número de consumidoras de literatura. Isso ressoou ideologicamente e promoveu discussões a respeito de quais seriam os tipos de leitura mais adequados para o público feminino. Condenaram-se gêneros e preferências e acusaram-se de vicioso o gosto de ler, por desviar a mulher das tarefas domésticas (LAJOLO;

\section{ZILBERMAN, 2003).}

A acessibilidade das mulheres à informação aumentou no século XIX. Contudo, a maior diferença entre a leitura feminina e a masculina ficava a cargo do conteúdo (DUMONT e ESPÍRITO SANTO, 2007). "A elas eram dedicados os romances da vida interior, uma leitura que objetivava o divertimento; aos homens, as notícias sobre eventos públicos, uma leitura que objetivava a informação e o estudo" (DUMONT e ESPÍRITO SANTO, 2007, p. $6)$.

Foi com a emergência da sociedade burguesa e suas estruturas produtivas de ideias e mercadorias que surgiu a genuína autonomia da esfera privada em contraposição à pública. O termo privado denominaria todos os atos, negócios, cargos, ou casa e indivíduos excluídos da autoridade pública. O público, por sua vez, assumiria dois sentidos: um referente a relações, ações, cargos, instituições e prédios ligados ao governo, e outro às ações e manifestações produzidas pela imprensa para se obter publicidade $\mathrm{e}$ opinião pública (HABERMAS, 1984 apud GENTILLI, 2002, p. 6).

Historicamente, o espaço público foi dominado por homens, enquanto que o privado e doméstico ficava a cargo das mulheres. A narrativa histórica tradicional reservou-lhes pouco espaço, justamente na medida em que privilegiou a cena pública - a política, a guerra - onde elas pouco apareciam (PERROT, 2005, p. 33). Assim, a memória feminina constituiu-se como uma memória do privado, voltada para o íntimo e para a família, lugares a que elas 
(as mulheres) foram delegadas, de certa forma, por convenção e posição (PERROT, 2005)

Por outro lado, é importante destacar que as mulheres chegaram a participar ativamente na vida pública. Enquanto, de um lado, havia uma sociedade burguesa com as mulheres delegadas ao espaço privado e os homens ao público, de outro havia uma classe operária com participação ativa feminina. As mulheres também trabalhavam nas fábricas e lutavam por seus direitos com a diferença de que, no espaço público, tinham que enfrentar uma forte reprovação e desconfiança da sociedade. Elas eram menosprezadas porque consideravam o seu comportamento ridículo e inadequado. A questão do gênero, em si, trazia relações de desigualdade na luta pelo poder, na esfera pública (TILLY, 1994).

Ao lado dos ideais iluministas de progresso e inclusão social, no século XIX, havia um processo marcado pela seleção e classificação de um conhecimento legítimo e legitimador, visto que orientar o acesso público não significa tornar todo saber legítimo. Assim, a ordem que foi estabelecida como base para estruturar a informação tornou-se a ordem da verdade no horizonte de consenso entre os poderes instituídos e instituidores e os públicos leitores (CRIPPA e ALMEIDA, 2005, p. 285).

Segundo Pinheiro (2011), a regra parecia simples. Era preciso controlar o que as mulheres liam a fim de mantê-las dentro do que era visto como a "normalidade". Assim, ao longo da história, elas tiveram que romper com os padrões impostos para participarem do processo de leitura e de escrita. Acreditava-se que ler demais era desnecessário e acabava trazendo malefícios para o sexo feminino. Os textos recomendados, portanto, seriam "os livros religiosos e, no máximo, romances para moças" (SCHOLZE, 2002, p. 29). A censura não diz respeito apenas à possível
ameaça que os romances e folhetins causariam à
formação feminina. Tentava-se impedir o acesso
das mulheres à literatura científica, aos temas
políticos e a outros assuntos ditos graves e que
não eram considerados de competência das
mulheres (LACERDA, 2003, p. 285).

A leitura em excesso era vista como perigosa e patológica porque associava a imobilidade do corpo com a excitação da imaginação. A atividade solitária da leitura conduziria a uma recusa da realidade em favor da quimera. O perigo era maior quando se tratava da leitura de um romance e quem o lia era uma mulher, no retiro da solidão (CHARTIER, 2007, p. 263).

Para Vieira (2010), surgiram novos suportes de leitura, novos meios e tecnologias. Porém, o imaginário acerca das mulheres leitoras não foi alterado, visto a representação das mesmas em mídias como o cinema e a literatura. Segundo a autora, persistem "formas coercitivas bastante sutis que continuam a aparecer sob novos discursos de repressão à leitura" (VIEIRA, 2010, p. 10).

Na literatura, um exemplo clássico do perigo da imaginação, para as mulheres, está presente no livro Madame Bovary, de Gustave Flaubert. Nele, a personagem central sofre as

Dossiê Práticas e Políticas Culturais: Paradoxos e diálogos com a tecnologia

Arquivos do CMD, Volume 5, N.1. Jan/Jul 2017 
consequências de sua leitura. "Ao procurar desesperadamente fazer sua realidade mais parecida com suas fantasias inspiradas pela literatura, Ema subverte a lógica do seu mundo prosaico e caminha para a tragédia" (SAMPAIO, s/d). O livro teve sua primeira edição no século XIX e representou muito bem a visão da sociedade nessa época em que, "para proteger a 'moral' feminina, padres, médicos, políticos discursaram sobre a importância de delimitar o acesso das mulheres à leitura" (PINHEIRO, 2011, p. 71). Acreditava-se, então, que a leitura era perigosa para as mulheres e deveria ser controlada. Os romances eram os principais tipos de leituras indicadas ao sexo feminino pela justificativa de que eles iam de acordo com a sua natureza. Ao mesmo tempo, um dos maiores receios era que as mulheres confundissem a literatura com a realidade. Havia ainda um paradoxo na questão da leitura feminina. Embora não fosse conveniente, para pais e maridos, que as mulheres lessem muito ou lessem "errado", os editores e vendedores festejavam os lucros advindos do seu novo público consumidor (LAJOLO; ZILBERMAN, 2003).

$\mathrm{Na}$ tentativa de construção desse público, as leituras eram tuteladas (MORAIS, 200?). Isso pode ser observado através de uma obra de Bettencourt (1885 apud Morais 200?), no século XIX, em que ela afirmava a existência de muitos discursos contra os romances pelo fato de eles serem prejudiciais à mocidade e pouco proveitosos como fonte de conhecimento. Por outro lado, Rodriguez (2005) fez uma pesquisa com leitoras de romances e percebeu que a grande maioria não era consumidora passiva. Da mesma forma que os textos interferiam nas vidas das leitoras, estas também ressignificavam o que liam, elaborando, através das narrativas, percepções que refletiam e reforçavam seus próprios valores. De acordo com Martín-Barbero (1997, p. 289), é fundamental a compreensão da natureza comunicativa da cultura. "Isto é, seu caráter de processo produtor de significações e não de mera circulação de informações, no qual o receptor, portanto, não é um simples decodificador daquilo que o emissor depositou na mensagem, mas também um produtor".

\section{Acesso orientado de leitura}

Após algumas considerações históricas sobre o acesso à informação pelas mulheres, observa-se que, embora não existam mais proibições de leitura na sociedade ocidental, as fontes de informação continuam demarcadas por questões de gênero. Programas de televisão, como o Mais Você e o Saia Justa, dizem ser dedicados ao universo feminino e tratam, essencialmente, de moda, beleza, culinária, saúde, decoração, maternidade e comportamento. As revistas femininas, como Claudia e Marie Claire, também seguem esse mesmo padrão.

A ludicidade e a superficialidade das leituras femininas parecem ter se mantido com o passar do tempo, apesar das transformações ocorridas com as mulheres. É claro que não se deve generalizar um aspecto tão individual e que diz respeito às práticas de leitura das mulheres, mas 
o que parece, e isto é evidenciado pelo estilo das publicações destinadas a esse público, é que a leitura para as mulheres tem como objetivo primordial o entretenimento e não a informação (KLEIN; RAMOS, 2006, p. 5)

$\mathrm{Na}$ verdade, elas informam de alguma maneira. Porém, estas informações são marcadamente de gênero, muitas vezes ligadas à autoajuda e à culinária, privilegiando o ambiente doméstico. Segundo Buitoni (1986), a imprensa feminina é um conceito sexuado. Desde que surgiram os primeiros periódicos femininos, no século XVII, eles foram direcionados às mulheres e, muitas vezes, produzidos por elas também. Na imprensa em geral, não existia essa distinção de público, embora a maioria dos leitores fossem homens devido às questões de letramento e acesso.

A própria conceituação de público, por sua vez, mudou várias vezes ao longo da modernidade. Antes do século XVII, pubblicus era visto como algo comum (de uso livre e universal com a água e o ar). No século XVIII, com a insurgência das monarquias absolutistas, o conceito de público passou a ser tratado como estatal (pertencente ao Estado). Apenas no século XIX que este termo teve uma conotação socioeducativa e o conceito de público tornou-se aquilo que pertence e serve ao público, ao povo. Desse modo, é comum haver uma oposição entre a imprensa feminina e a imprensa em geral. Esta é vista como jornalismo sério baseado em fatos. Aquela costuma ser classificada como jornalismo de entretenimento ou como "não jornalismo".
O elemento base da teoria do jornalismo é a notícia ou, em termos mais modernos, a informação que deve estar ligada a um fato novo. Assim, no sentido de registro do fato, a atualidade não está muito presente na imprensa feminina devido a seus conteúdos tradicionais: moda, beleza, culinária, decoração [...] (BUITONI, 1986, p. 13). Ao invés de notícias, a imprensa feminina costuma apresentar novidades, ou melhor, modismos que se colocam como aquilo de mais atual. Assim, na teoria, a imprensa feminina se afasta do jornalismo. Mas, segundo Buitoni (1986, p. 12), "existe um jornalismo feminino baseado na notícia e, embora a imprensa feminina seja passível de críticas, os critérios para análise não devem partir da oposição jornalismo/não jornalismo”. É necessário analisar a ideologia por trás dos conteúdos que moldaram e ainda moldam as revistas femininas de hoje.

Elas veiculam o que é considerado "mundo feminino" pelos seus contemporâneos, são capazes de formar gostos, opiniões, padrões de consumo e de conduta e, muitas vezes, servem como guias de ação, conselheiras persuasivas e companheiras de lazer. Uma das suas funções é a de proporcionar a venda e o lucro. Assim, elas tendem a não se arriscar com ideias revolucionárias e preferem reproduzir o aparente consenso social a respeito do masculino e do feminino. Com efeito, o conteúdo de suas publicações acaba mantendo e legitimando as relações de poder existentes (BASSANEZI, 1996). 
As revistas tentam corresponder à demanda do público leitor, considerando seu modo de agir e pensar, ao mesmo tempo em que procuram discipliná-lo e enquadrá-lo nas relações de poder existentes, funcionando como um ponto de referência, oferecendo receitas de vida, impingindo regras de comportamento, dizendo o que deve e principalmente o que não deve ser feito (BASSANEZI, 1996, p. 16).

Nesse sentido, os temas direcionados ao público feminino continuam estereotipados no século XXI, recomendando os padrões sociais de forma física, vestuário e comportamento. A mulher ainda é reduzida à sua condição de mãe, responsável pelos afazeres do lar e objeto de satisfação sexual do homem. Desse modo, textos que se apresentam como lazer trazem padrões de comportamento subjacentes que visam à manutenção de um paradigma social (ESTEVES; SIMÕES, 2009).

Feitas essas considerações, é importante falar sobre o espaço que cada uma das revistas e programas dedica para a indicação de leituras, compreendendo o período analisado, de 2011 a 2012. Quanto à revista Claudia, ela possui algumas páginas editadas por Adriana Negreiros e denominadas de Inspiração. Assim, os livros são indicados em Inspiração - Cultura ou Inspiração - Este mês eu quero. Mas, existem ainda as páginas de Inspiração - Gente, Inspiração - Tendência, Inspiração - Tecno, Inspiração - Carreira e Inspiração - Conversa com Danusa.

Já a revista Marie Claire chegou a mudar o nome de suas páginas dedicadas à leitura no período estudado. De 2011 a abril de
2012, elas eram denominadas de Pré-estreia e editadas por Laura Ancona Lopez e Ana Carolina Ralston. Os livros eram indicados em Pré- estreia - Livros. Mas, também havia Pré-estreia - Artes e Espetáculos, Pré-estreia - Televisão, Pré-estreia - Cinema, Préestreia - Música e Pré-estreia - Beber, comer e dançar. No entanto, a partir de maio de 2012, as páginas direcionadas a assuntos semelhantes a esses passaram a ser chamadas de Zoom, mantendo Lopez e Ralston como editoras. Assim, os livros começaram a ser indicados em Zoom - Literatura, acompanhados pelo Zoom - Música, Zoom - Arte, Zoom - Cinema, Zoom Exposição, Zoom - Gastronomia e Zoom - Agenda do Mês.

Quanto ao programa Mais Você, Temer (2006) faz uma análise sobre ele e o denomina de "revista feminina na televisão". A autora defende que tanto as revistas como os programas de televisão femininos não devem ser classificados apenas como entretenimento, afinal eles também possuem "entrevistas e reportagens, que são indubitavelmente formatos jornalísticos" (TEMER, 2006, p. 4). Por outro lado, as questões de gênero ainda prevalecem. "Os programas femininos em tv obedecem uma lógica nefasta e repetitiva: retratam o cotidiano feminino de forma reduzida, naturalizado em ações repetitivas, ligados aos cuidados da família e do lar" (SILVA, 2001, p. 2).

No Mais Você, as indicações de leitura são provenientes de entrevistas com escritores que divulgam as suas obras no programa, de reportagens a respeito de livros que as pessoas gostam de ler ou

Dossiê Práticas e Políticas Culturais: Paradoxos e diálogos com a tecnologia

Arquivos do CMD, Volume 5, N.1. Jan/Jul 2017 
do incentivo à leitura através de um quadro denominado pela apresentadora como o "cafofo da leitura", em que ela ou outras pessoas dão sugestões sobre livros. Já no Saia Justa, as indicações de filmes, músicas e livros são bastante comuns no programa e surgem durante os debates, a partir do momento em que as apresentadoras os relacionam com os temas discutidos.

Após uma análise sobre o que foi sugerido como leitura nas revistas e nos programas, percebeu-se que houve uma diferença considerável entre as sugestões. A maioria dos livros indicados pelas revistas foram aqueles lançados recentemente, acompanhando a linha de "novidade" proposta pelas revistas femininas, como diz Buitoni (1986). A tendência dos programas, por outro lado, foi a indicação de obras clássicas e premiadas.

Foi possível observar ainda que houve uma manutenção dos estereótipos de gênero nessas indicações. Dessa forma, acredita-se que o controle que existia nos séculos XVIII, XIX e XX continua atualmente por meio de instrumentos que sugerem determinadas leituras para as mulheres, fazendo com que haja um acesso orientado de leitura. Através de uma pesquisa realizada na comunidade virtual $S k o o b$, verificou-se ainda que há uma resposta positiva quanto a esse ideal de leitora que existe no imaginário das pessoas que trabalham nas revistas e nos programas citados anteriormente. A Skoob possui uma ferramenta que nos possibilita a verificação da porcentagem de mulheres e de homens que leram determinados livros e é por meio dela que a análise foi realizada.

\section{A leitora hoje}

De acordo com a terceira edição da pesquisa Retratos $d a$ Leitura no Brasil, desenvolvida em 2011 pelo Instituto Pró-Livro, as mulheres costumam ler mais do que os homens. Segundo o PNAD (Pesquisa Nacional por amostra de Domicílios), em 2009 a população total do Brasil era composta por 191.435 .389 de habitantes. O universo da pesquisa Retratos da Leitura no Brasil, por sua vez, refere-se a 93\% dessa população (178.082.033), considerando as pessoas com mais de 5 anos, alfabetizadas ou não. Desse modo, verificou-se que $50 \%$ dos brasileiros podem ser considerados leitores. A categoria leitor foi definida como aquele que leu, inteiro ou em partes, pelo menos um livro nos últimos 3 meses. Assim, entre os homens, $43 \%$ foram considerados leitores e, entre as mulheres, $57 \%$.

Já em relação à média de livros lidos nos últimos 3 meses, o sexo masculino leu 0,62 livros inteiros e 1,01 em partes, enquanto o sexo feminino leu 1,02 livros inteiros e 1,05 em partes. No total, os homens leram, em média, 1,63 livros e as mulheres 2,07. Quanto à penetração de leitura, dos 88,2 milhões (50\%) de pessoas consideradas leitoras pela pesquisa, 38,3 milhões (44\%) são do sexo masculino e 49,9 (54\%) são do sexo feminino. Ainda de acordo com a pesquisa, $24 \%$ das pessoas entrevistadas frequentam a biblioteca e $76 \%$ não frequentam. Dentre os que frequentam, 55\% são mulheres e $45 \%$ homens. Observa-se também que, entre os 25 escritores 
brasileiros mais admirados, apenas três mulheres foram citadas: Zíbia Gasparetto, Cecília Meireles e Clarice Lispector (FAILLA, 2012).

Esses dados sugerem que, embora poucas pessoas brasileiras tenham o hábito de ler e de frequentar uma biblioteca, a maioria delas são mulheres. Por outro lado, quase não houve escritoras citadas como mais admiradas pelo público brasileiro, o que revela um silenciamento da literatura de autoria feminina. Através da análise realizada a fim de verificar as indicações de leitura presentes em algumas revistas e programas voltados ao público feminino, foi possível notar que a maioria recomendou livros que vão de acordo com o imaginário que a sociedade possui sobre as mulheres. $\mathrm{Na}$ comunidade $S k o o b$, as porcentagens de gênero e os comentários de leitoras e leitores, em geral, também reforçaram esses estereótipos.

Os livros relacionados ao gênero chick-lit, por exemplo, tiveram uma maior porcentagem de leitura feminina. Este gênero, conhecido também como "literatura de mulherzinha", é voltado às mulheres urbanas, profissionais e marcadas por problemas amorosos e sexuais (LEAL, 2010). Desse modo, há uma ambiguidade presente na maioria das obras, visto que algumas temáticas feministas, geralmente relacionadas à independência financeira das mulheres, "terminam por se diluírem na forma pelas quais são apresentadas, em meio ao mundo do consumo, da moda e da reatualização da busca do príncipe encantado" (LEAL, 2010, p. 3).

Outros livros que também apresentaram uma porcentagem bem maior de leitura feminina foram o Cinquenta tons de cinza e o Toda Sua. Ambos correspondem ao gênero mommy-porn (pornô para mamães), em que "há a dominação sexual do personagem masculino sobre as protagonistas - indo na contramão dos discursos feministas" (ZANOLI, 2012). A alta porcentagem de leitura realizada pelas mulheres foi observada ainda nos livros de autoajuda ligados a relacionamentos amorosos ou modelos de comportamento. O mesmo aconteceu com livros sobre religião e culinária. No entanto, aqueles que foram escritos por chefes de cozinha masculinos tiveram uma diferença menor ou uma igualdade na porcentagem de gênero.

Os livros relacionados à moda e à perda de peso também apresentaram um maior público leitor feminino, assim como o livro Feliz por nada, que foi escrito por Martha Medeiros. Segundo Freire (2009), esta é uma autora que entende os limites do estereótipo como algo negativo. Mas, a sua crítica funciona apenas quando ela foca as mulheres em relação a elas mesmas porque, se a perspectiva está sobre os homens, Martha Medeiros não considera a diversidade e mantém uma polarização entre masculino-feminino.

Os livros do gênero romance, em geral, também tiveram uma maior porcentagem de leitura feminina. Mas, quando o protagonista era masculino, o livro era histórico ou falava sobre sexo de um modo mais aberto, a situação se modificava e os homens eram o maior público leitor. Já os livros que destacavam a figura de uma personalidade masculina conhecida pelo público ou 
de homens ligados ao poder e à tecnologia, tiveram uma maior porcentagem de leitura masculina. Com os livros de autoajuda relacionados à inteligência, à carreira profissional e à internet, a situação não foi diferente. $\mathrm{O}$ mesmo aconteceu com os contos e frases de Nelson Rodrigues. Ele é conhecido por expor o seu ponto de vista a respeito das mulheres. De acordo com Zechlinski (2007, p. 426), a maioria dos contos deste autor faz parte da "reação contrária às mudanças, de forma a manter a mulher no seu papel de mãe e dona-de-casa, assim como preservar a autoridade masculina na família".

Todavia, alguns casos precisam ser considerados à parte. Rihanna é uma biografia sobre uma cantora e teve um pouco mais de leitura masculina. Fique mais jovem a cada ano também fugiu do que se era esperado ao ter mais leitores do sexo masculino, visto que a beleza é muito mais cobrada, pela sociedade, em relação ao sexo feminino. Em geral, o imaginário de que as mulheres se interessam por livros do gênero romance e por temas como culinária, moda, beleza, religião e relacionamentos amorosos foi confirmado através dos dados do Skoob. Porém, isso não significa que as mulheres gostam, naturalmente, desses assuntos. Na verdade, esse imaginário é naturalizado pela sociedade e pela mídia e, culturalmente, interfere nas escolhas de leitura do sexo feminino.

\section{Considerações finais}

As mulheres, em relação aos homens, tiveram um acesso tardio à educação. Acreditava-se que elas não precisavam estudar porque eram destinadas à vida doméstica e, sendo assim, apenas aquelas que tinham um poder aquisitivo maior acabavam aprendendo a ler e a escrever. No século XVII, aumentou a preocupação em educar as mulheres, mas ainda com uma visão de que o ensino para elas deveria ser diferente do que era para os homens e que o importante era educá-las a fim de que elas educassem os seus filhos. Ou seja, o mundo privado ainda seria o essencial para o sexo feminino.

De qualquer modo, a partir desse momento a leitura começou a fazer parte do cotidiano de muitas mulheres. No entanto, nem todos os livros eram vistos como adequados e permitidos para a mulher. Aqueles relacionados à política, ciência e filosofia, por exemplo, eram considerados muito complexos e, assim, o romance acabou sendo mais difundido e tornou-se sinônimo de leitura feminina. Mesmo entre os romances, havia uma política de censura em relação aos que tratavam de assuntos tidos como impróprios, entre eles a liberdade sexual e o adultério.

Em relação às análises que foram realizadas a respeito dos livros indicados nas revistas e nos programas, verificou-se que as questões de gênero ainda prevalecem quando se trata do imaginário social que existe sobre as mulheres leitoras. Os veículos de comunicação, em geral, indicam os livros de modo tendencioso, naturalizando as diferenças entre o sexo feminino e masculino. Todavia, a cultura em torno dessas diferenças deveria ser deslocada

Dossiê Práticas e Políticas Culturais: Paradoxos e diálogos com a tecnologia

Arquivos do CMD, Volume 5, N.1. Jan/Jul 2017 
do determinismo biológico para as construções sociais, relacionais e culturais. "Para a perspectiva de gênero, a mulher é definida como um ser histórico, gerado pelas relações culturais de acordo com valores e hierarquias sociais que estão interligados a fatores políticos e econômicos, em cada sociedade" (ESPÍRITO SANTO, 2008, p. 3). Desse modo, é uma categoria relacional, visto que homens e mulheres só se definem numa relação entre um e outro (ESPÍRITO SANTO, 2008).

Apesar da possibilidade de acesso à informação ter aumentado com o desenvolvimento da tecnologia, observou-se que os livros considerados como "femininos" foram lidos mais pelas mulheres. Além disso, quando algum livro indicado nas revistas ou programas tratava de assuntos tidos como "masculinos" pelo senso comum, ele tinha um maior número de leitores do que leitoras. Ou seja, a recepção dos livros na Skoob foi de acordo com uma cultura sexista que está profundamente enraizada na sociedade.

Embora não existam mais proibições oficiais de leitura, e o acesso à informação seja facilitado pela tecnologia, as leituras ainda são indicadas de modo estereotipado para os homens e as mulheres, e a sociedade reflete esses estereótipos de leitura. Porém, é preciso considerar que a pesquisa possui um recorte específico, visto que as revistas estudadas são acessíveis a um público com maior poder aquisitivo, o programa Saia Justa passa na televisão por assinatura e apenas o Mais Você é transmitido pelo canal aberto. O estudo da recepção dos livros na comunidade Skoob também possui limitações porque abrange pessoas que têm acesso à internet e participam desta comunidade virtual. De qualquer modo, acredita-se que o mapeamento realizado pela pesquisa é relevante, e esses questionamentos devem ser levados adiante para que se tente promover algum tipo de mudança na sociedade.

\section{Referências}

BASSANEZI, C. Virando as páginas, revendo as mulheres: revistas femininas e relações homem-mulher (1945-1964). Rio de Janeiro: Civilização brasileira, 1996. 499 p.

BEAUVOIR, S. O segundo sexo. São Paulo: Difusão Européia do Livro, 1970. BUITONI, D. S. Imprensa feminina. São Paulo: Ática, $1986.96 \mathrm{p}$.

CHARTIER, R. Inscrever e apagar: cultura escrita e literatura São Paulo: Editora UNESP, 2007. 335p.

CRIPPA, G.; ALMEIDA, M. A. Transformações da esfera pública na sociedade da informação: pensando mídia, guerra e cultura. Projeto História, v. 30, p. 277-299, jun. 2005. Disponível em: <http://revistas.pucsp.br/index.php/revph/article/view/2267/1361>. Acesso em: 26 out 2015.

DUMONT, L. M. M.; ESPÍRITO SANTO, P. Leitura feminina: motivação, contexto e conhecimento. Ciências \& Cognição, v. 10 p. 28-37, 2007. Disponível em: <http://www.cienciasecognicao.org/revista/index.php/cec/article/vie w/618/400>. Acesso em: 26 out. 2015.

ESPÍRITO SANTO, P. Os estudos de gênero na ciência da informação. Em Questão, Porto Alegre, v. 14. n. 2, p. 317-332, jul./dez. 2008. Disponível em <http://seer.ufrgs.br/EmQuestao/article/view/6389/4877>. Acesso em: 26 out. 2015 .

ESTEVES, F. C; SIMÕES, D. M. P. Revistas femininas: contra ou a

Dossiê Práticas e Políticas Culturais: Paradoxos e diálogos com a tecnologia

Arquivos do CMD, Volume 5, N.1. Jan/Jul 2017 
favor da mulher? Cadernos do CNLF, v. 13, n. 4, p. 1132-1140, 2009. Disponível

<http://www.filologia.org.br/xiiicnlf/resumos/revistas_femininas_co ntra_flavia_cassino.pdf $>$. Acesso em: 26 out. 2015.

FAILlA, Z. (Org.) Retratos da leitura no Brasil 3. São Paulo: Imprensa Oficial do Estado de São Paulo: Instituto Pró-Livro, 2012. 344p.

FREIRE, S. B. S. A crônica contemporânea de autoria feminina: Lya Luft, Marina Colasanti e Martha Medeiros. 2009. 108 f. Dissertação (Mestrado em Letras Vernáculas - Literatura Brasileira) - Faculdade de Letras, Universidade Federal do Rio de Janeiro, Rio de Janeiro, 2009.

GENTILLI, V. O conceito de cidadania, origens históricas e bases conceituais: os vínculos com a Comunicação. Revista FAMECOS: mídia, cultura e tecnologia, v. 1, n. 19, p. 1-38, 2002. Disponível em:

<http://www.revistas.univerciencia.org/index.php/famecos/article/vi ew/325/256> Acesso em: 26 out. 2015 .

HELLER, B. Vossas filhas sabem ler? In: CONGRESSO BRASILEIRO DA COMUNICAÇÃO, 24., 2001, Campo Grande. Anais... Campo Grande: INTERCOM, 2001. Disponível em: <http://www.intercom.org.br/papers/nacionais/2001/papers/NP4HE LLER.pdf>. Acesso em: 26 out. 2015.

KLEIN, J. J.; RAMOS, F. B. Revistas femininas: construindo a imagem da mulher-leitora. UNISC, Santa Cruz do Sul, 2006. Disponível

<http://www.unisc.br/portal/images/stories/mestrado/letras/coloquio s/ii/revistas_femininas.pdf >. Acesso em: 26 out. 2015

LACERDA, L. Álbum de leitura: memória de vida, histórias de leitoras. São Paulo: Editora Unesp, 2003. 498p.

LAJOLO, M.; ZILBERMAN, R. A formação da leitura no Brasil São Paulo: Ática, 2003. 374p.

LEAL, V. M. V. O gênero em construção nos romances de cinco escritoras brasileiras contemporâneas. In: DALCASTAGNÈ, $R$ LEAL, V. M. V. (Orgs.). Deslocamentos de gênero na narrativa brasileira contemporânea. São Paulo: Editora Horizonte, 2010. p. 65-96.

MARTÍN-BARBERO, J. Dos Meios Às Mediações: cultura, comunicação e hegemonia. Rio de Janeiro: UFRJ, 1997.

MORAIS, M. A. C. Revisitando romances do século XIX: análise sobre a formação da leitora brasileira. Natal, Universidade Federal do Rio Grande do Norte, [200?]. Disponível em: <http://www2.faced.ufu.br/colubhe06/anais/arquivos/105MariaAris neteCamaraMorais.pdf>. Acesso em: 26 out. 2015

PERROT, M. As mulheres ou os silêncios da história. Bauru EDUSC, 2005. 519p.

PINHEIRO, A. S. Mulheres e leitura: entre regras sociais e escolhas pessoais. Educacão e Fronteiras On-Line, Dourados/MS, v. 1, n. 2, p. 62-76, mai./ago. 2011. Disponível em:

$<$ http://www.periodicos.ufgd.edu.br/index.php/educacao/article/vie wFile/1450/pdf_81>. Acesso em: 26 out. 2015.

RODRIGUEZ, S. M. Leitoras com coração: usos de leitura dos romances sentimentais de massa. Revista Letras, Curitiba, n. 65, p. 23-37, jan./abr 2005. Editora UFPR. Disponível em: <http://ojs.c3sl.ufpr.br/ojs2/index.php/letras/article/view/4294/3443 . Acesso em: 26 out. 2015.

SAMPAIO, I. S. Ema Bovary, leitora de romances. Campinas: Unicamp, s/d [200?]. Disponível em: < http://www.fe.unicamp.br/alle/textos/ISS-EmaBovary.pdf >. Acesso em: 26 out 2015

SCHOLZE, L. A mulher na literatura: gênero e representação Gênero, v.3, n.1, p.27- 33, 2002. Disponível $<$ http://www.ieg.ufsc.br/admin/downloads/artigos/01112009094117scholze.pdf >. Acesso em: 26 out. 2015

SILVA, M. L. Programas femininos em televisão: perspectivas multiculturais. Rastros, v. 3, n. 3, 2001. Disponível em: 


\section{Larissa Alccabochi dedcarvalho}

<http://www.portcom.intercom.org.br/pdfs/a1f0c4a2feb01f8218d7c 47111add2df.pdf $>$. Acesso em: 26 out. 2015.

SPIVAK, G. C. Pode o subalterno falar? Belo Horizonte: Editora UFMG, 2010. 133p.

TEMER, A. R. P. Mais Você: uma análise da revista feminina na televisão. In: CONGRESSO BRASILEIRO DE ESTUDOS INTERDISCIPLINARES DA COMUNICAÇÃO - Intercom, 28., 2006, Rio de Janeiro. Anais... Rio de Janeiro: UERJ, 2006

TILLY, L. A. Gênero, história das mulheres e história social Cadernos Pagu, Campinas, n. 3, p. 28-62, 1994. Disponível em: $<$ http://periodicos.bc.unicamp.br/ojs/index.php/cadpagu/article/view /1722/1706>. Acesso em: 26 out. 2015

VIEIRA, N. R. F. Novas leitoras, antigos cenários. In: ENCONTRO DE ESTUDOS MULTIDISCIPLINARES EM CULTURA, 6. 2010, Bahia. Anais Eletrônicos... Salvador: ENECULT, 2010. Disponível em: <http://www.cult.ufba.br/wordpress/24935.pdf>. Acesso em: 26 out. 2015 .

ZANOLI, T. Erotismo para as mamães: best-sellers, livros eróticos conquistam mulheres casadas. A Gazeta: para você que espera muito mais de um jornal (gazetaonline), 2012. Disponível em: <http://gazetaonline.globo.com/ conteudo/2012/08/noticias/a gazet a/caderno_2_ag/134 0546-erotismo-para-as-mamaes.html> Acesso em: 26 out. 2015

ZECHLINSKI, B. P. - A vida como ela é...l: imagens do casamento e do amor em Nelson Rodrigues. Cadernos Pagu, Campinas, n. 29, jul./dez. 2007. Disponível em:

$<$ http://www.scielo.br/scielo.php?pid=S0104-

$83332007000200016 \&$ script $=$ sci arttext\&tlng $=p t>$. Acesso em: 26 out. 2015. 